\title{
Evoked Culture and Evoked Nature: The Promise of Gene-Culture Co-Evolution Theory for Sociology
}

\author{
Anthony Walsh ${ }^{1 *}$ and Ilhong Yun ${ }^{2}$ \\ ${ }^{1}$ Department of Criminal Justice, Boise state University, Boise, ID, USA, ${ }^{2}$ Department of Police Administration, \\ Chosun University, Gwangju, South Korea
}

The traditional sociological view of culture has been almost exclusively that of transmitted culture decoupled from biology. The concept of evoked culture brings biology "back in" since it identifies ecological challenges that evoked certain practices based on evolutionary imperatives. The practices are then passed on to subsequent generations as normative, and individuals best suited to these normative practices will enjoy greater fitness benefits than those less suited. In other words, practices will be transmitted genetically as well as culturally. This paper provides several examples of how evoked and transmitted culture are tightly bound (nature evoked by culture, and culture evoked

OPEN ACCESS

Edited by:

Susanne Huber,

University of Vienna, Austria

Reviewed by:

Joseph L. Nedelec,

University of Cincinnati, USA

Daniel E. Adkins,

Virginia Commonwealth

University, USA

*Correspondence:

Anthony Walsh

twalsh@boisestate.edu

Specialty section: This article was submitted to Evolutionary Sociology and Biosociology,

a section of the journal

Frontiers in Sociology

Received: 04 March 2016 Accepted: 24 June 2016 Published: 19 July 2016

Citation:

Walsh A and Yun I (2016) Evoked

Culture and Evoked Nature:

The Promise of Gene-Culture Co-Evolution Theory for Sociology.

Front. Sociol. 1:8.

doi: 10.3389/fsoc.2016.00008 by nature) as well as identifying two specific genetic polymorphisms associated with adaptive approach-avoidance behaviors and found in highly variable frequencies in different cultures around the world. We argue that an appreciation of evoked culture complements transmitted culture and deepens and broadens our understanding of cultural life and practices.

Keywords: evoked culture, gene-culture co-evolution, polymorphisms, serotonin, dopamine

Turner (2007:357), notes that social theorizing tends to take place within a philosophical framework that is in "potential conflict" with natural science. His point is that the phenomena of sociology are mostly intangible concepts, such as "society," "norms," and "values" as opposed to the tangibles of natural science. This does not mean that sociology has to be in conflict with natural science. Sociology's disengagement from biology arguably began with Auguste Comte's dismissal of psychology as metaphysical, which ruled out sociological interest in the brain. Its embrace of Durkheim the social factist and the rejection of the Durkheim of Homo duplex (Layton, 2010) led to sociology's wholesale dismissal of the natural sciences. This rejection was and is ill-advised since the natural sciences have a lot to teach us. In his Presidential Address to the ASA, Douglas Massey (2002:1) made much the same point: "Sociologists have allowed the fact that we are social beings to obscure the biological foundations upon which our behavior ultimately rests". Our emphasis in this paper that over the expanse of evolutionary time nature and nurture - genes and culture - have been mutually evocative, and what has emerged from this interplay can be fruitfully examined from both traditional sociological and biosociological frameworks.

\section{CULTURE: TRANSMITTED AND EVOKED}

Transmitted culture is the spread of mental representations of knowledge, meaning, and value from person to person across the generations via non-genetic means. This concept of culture dominates sociology where it is viewed as a phenomenon decoupled from biology (Cohen, 2010). Although 
transmitted culture is vital for understanding human behavior and cultural variation, it has a symbiotic partner - evoked culture. The concepts of evoked and transmitted culture are complementary distal and proximate explanations that should be recognized as inseparable approaches that help us to avoid naïve naturenurture arguments. Schaller (2006:100), notes that: "Behind the concept of evoked culture lurk many wonderful findings from research in evolutionary theory and behavioral ecology." We are not claiming that integrating the concept of evoked culture will revolutionize sociology, or even the way sociologists examine transmitted culture. It is a powerful additional conceptual tool with a materialist base that will help us tie our research and theory to a broader research community.

Genes and culture are both information transmission devices; the former laying the foundation for the latter, and the latter then influencing the former (what genetic variants are adaptive in this culture at this time). Moya and Henrich (2016:112), inform us that it is "uncontroversial that both genes and culture shape human psychology. However, recent evolutionary processes go one step further in formalizing the selection processes whereby both genetic and cultural traits can change through time and produce functional psychological mechanisms for facing adaptive challenges." Kashima (2016:8), calls this "step further" in gene-culture co-evolution "naturalizing culture," and asserts that its goal is to "uncover ecological correlates of culture."

Central to the concept of evoked culture is the notion that fitness-relevant cultural practices are triggered by the challenges presented by ecological conditions over evolutionary time, and to the extent that they proved to be adaptive, they became culturally entrenched and transmitted as normative. Individual traits conducive to carrying out those practices are favored by selection, and the genes underlying them will proliferate down the generations. Behavioral patterns forged by ecology are perpetuated by transmitted culture normatively without members being aware of why (Brown et al., 2011). The entwined nature of transmitted and evoked culture is expressed by Cohen (2010:60): "many aspects of culture are synergistically evoked by the environment and ensconced in deeply felt and transmitted norms and values, and then transmitted by adherents of those cultures even after the groups no longer lives in the same ecology." Laland et al. (2010) catalog a cascade of genetic variants that have been subjected to positive selection in response to human cultural activities. While transmitted and evoked cultures are intertwined, many sociologists are opposed to the notion of evoked culture because of antiquated suspicions of "biological determinism" (Mesoudi, 2006). Such opposition may be muted with the realization that culture influences nature (evoked nature) just as actively as nature influences culture (evoked nurture) (Walsh and Bolen, 2012; McDermott and Hatemi, 2014; Kashima, 2016).

As an information filtering system that provides us with our sense of collective meaning, humans are cognitively coated in transmitted culture. Transmitted culture is a worldview ordering cognitive reality guiding individual's choices in ways that are presumably adaptive in their social environments. Like biological adaptations, culture fits us into our environments as comfortable as possible given existing conditions. But each new generation is not a clone of the previous one; culture is always in flux.
A useful concept to describe the evolution and perpetuation of cultural ideas is Richard Dawkins' notion of "memes." Dawkins originally chose the term as a rhetorical device to illustrate a larger evolutionary argument and to clarify his "selfish gene" argument, but it has undergone random mutations in its conception, which in itself proves the usefulness of the concept for illustrating the way cultural ideas are transmitted (Burman, 2012). As Dawkins (2006:192), described memes: "Examples of memes are tunes, ideas, catch-phrases, clothes fashions, ways of making pots or of building arches. Just as genes propagate themselves in the gene pool by leaping from body to body via sperms or eggs, so memes propagate themselves in the meme pool by leaping from brain to brain via a process which, in the broad sense, can be called imitation."

The fact that cultural differences in ideas, fads, fashions, artifacts, and practices flit in and out of vogue rapidly leads to the logical conclusion that culture could not possibly influence the human genome, nor could the genome influence culture. Furthermore, the preponderance of transmitted culture is fitnessneutral, and sometimes can even be antagonistic to genetic fitness. However, evoked culture focuses on cultural universals not cultural variety, and nothing rules out evolved genetic biases acting on cultural transmissions. Evoked culture has exacted a major influence on natural selection, is more circumscribed than transmitted culture, and ultimately rests on survival and reproductive imperatives (Brown et al., 2011; McDermott and Hatemi, 2014).

The concept of evoked culture includes within it the notion that humans have specialized adaptation for responding to a range of environmental challenges (acquiring food, territory, and mates, responding to natural disasters, avoiding disease, and so on) that had important fitness consequences over human phylogeny. Environmental challenges evoke certain patterns of behavior which are then elevated to the level of transmitted values and norms guiding the expected behavior of all who belong to the culture in question. Otherwise stated, there is a genetic canalization of social influences recursively interacting with a social canalization of genetic influences across generations $(\mathrm{McD}$ ermott and Hatemi, 2014).

The complementary nature of evoked and transmitted culture is exemplified by the universality of status striving and the variety of transmitted cultural practices that express it. It is a central tenet of evolutionary biology that status competitions among males are universal and are ultimately (albeit, unconsciously) about mate acquisition (Buss, 2001; Flinn, 2010). As Loch et al. (2006:222), remark: "People crave general respect and recognition in all cultures of the world. In other words, the striving for success is hard-wired, utilizing basic emotions (such as anger, sadness, happiness, pride) depending on whether status is achieved or not." Of course, status can be and is valued for its own sake and have nothing at all to do with mate acquisition, and the criteria by which status is attained are context specific. Nettle (2009:237), writes; "under conditions of competition for mates, men may be universally motivated to enter status competitions (evoked culture), but the local forms that status competition takes (praise-singing, jousting, potlatch, wrestling) could be transmitted." 
According to Turner (2007:364), it was largely the influence of Franz Boas that moved social scientists to view culture as a "denaturalized" autonomous causal agent constituted by "a shared set of presuppositions, values, and the like that was a more or less arbitrary selection from the basket of possible human values." Boas' view was that any cultural pattern of behavior is possible, and that humans have no natural constraints (other than physical ones) on those possibilities.

Mead's (1935) work among the Arapesh, Mundugumor, and Tchambuli peoples of New Guinea is the quintessential example of cultural practices apparently arising from nothing tangible and disconnected from nature. Although Mead's Sex and Temperament has been widely discredited (Gewertz and Errington, 1991; Roscoe, 2003), criticisms have been based almost entirely on her misinterpretations of the transmitted cultures of these three tribes. Even if her descriptions were accurate, describing differences between cultures is not explaining what lies behind them that make them different, and to do that we have to appeal to the ecology of a particular culture. Under harsh ecological conditions, survival and reproductive success depends on strong norms of cooperation, and traits associated with parenting effort are prized over traits associated with mating effort. Resource-rich ecologies, on the other hand, free males from having to demonstrate willingness to invest in offspring and long-term relationships, and mating effort is favored over parenting effort (Harpending and Draper, 1988; Buss, 2001; Lipset, 2003; Brown et al., 2011). In his analysis of human reproductive strategies in light of the $\mathrm{r} / \mathrm{K}$ continuum of reproductive strategies, MacDonald (1997:333-334), states:

Theoretically, high-investment parenting is associated with adaptation to ecologically adverse or highly competitive environments where high levels of parental investment are critical to rearing successful offspring. This makes intuitive sense because in ecologically adverse or highly competitive situations, male provisioning of food or other resources might tip the balance in favor of offspring compared to the offspring of males who do not provision their young. Indeed, several theorists have proposed that the adverse environment created by the Ice Age had an important role in shaping the intelligence and high-investment reproductive behavior of northern populations.

Within this framework, natural selection resulted in a uniform tendency toward high-investment parenting as a result of longterm resource scarcity: males who did not provision their young left few descendants. Long-term selection in resource-scarce environments is, therefore, expected to lead to high-investment parenting, not low-investment parenting.

If we look only at modern societies guided by life history theory, the relationships between resource availability, violence, and mating versus parenting effort are reversed. Instead of relatively small emotionally engaged groups of people submerged in Durkheimian mechanical solidarity, in organic urban societies we have large groups of relatively autonomous beings with weak emotional ties to the larger society and unconstrained by a strong collective conscience. The basic necessities are provided by the state in such societies, which free males prone to taking advantage of the states' largesse from their traditional roles of providers. Thus, altruistic cooperation is not an imperative to sheer survival as it is in prestate societies with scarce resources. Inhabitants of locales of scarce resources and weak normative controls in modern societies with little to lose are free to engage in violent competitions for access to mates, resources, and "street cred" (Anderson, 1999).

A contemporary example that directly engages the evolutionary imperatives of obtaining resources and acquiring mates is Guttentag and Secord's (1983) operational sex ratio (OSR) hypothesis. The OSR is the ratio of available sexually active males to available sexually receptive females in a population. Guttentag and Secord's (1983) survey of the effects of high and low OSRs from ancient Greece to the modern United States shows that when the OSR is high (more men than women), women are valued as long-term partners, marriage is highly valued, and sexually morality is stressed. In low OSR cultures, marriage rates drop, divorce and illegitimacy rates rise, women are largely valued as sex objects, and the cultural ambiance is licentious. Commenting on a low OSR in Medieval Germany and France, Guttentag and Secord (1983:69), write: "As expected from the low sex ratios, the prevailing ethos was sexual libertarianism, a cultural attitude shared by both men and women. Sexual cynicism, rather than the ideal of committed love, predominated. All aspects of society were touched by what has been referred to as 'the decline in morals."

This is similar to the modern United States which, according to the Census Bureau US (2014), had only 87 single men for every 100 single women in 2013. But moral decline is an effect rather than a cause, since historical data show that the ideational moral ambiance tracks the materialist mating environment rather than the other way around (Barber, 2003; Sober, 2007). The sex-steeped content of modern American culture is following the behavior of both sexes evoked in a male-favoring OSR. While many older Americans see this as disastrous, younger Americans who have not seen anything else, consider it normal. If history teaches us anything, if the OSR ever reverts to a female-favoring one, we will slowly see transmitted culture vis-à-vis sexuality reverting to a romance and marriage-supporting morality.

\section{GENE-CULTURE CO-EVOLUTION}

It used to be thought that gene-culture evolution was only salient during the Pleistocene epoch when cultural change was slower than genetic change, and that cultural evolution is too rapid for natural selection to track. New genetic technology, however, has shown that the rate of genomic change has been 100 times greater over the last 40,000 years than it was during the Pleistocene due to the greater challenges posed by living in ever larger social groups: "The rapid cultural evolution during the Late Pleistocene created vastly more opportunities for further genetic changes, not fewer, as new avenues emerged for communication, social interaction, and creativity" Hawks, et al. (2007:20757). Genetic mutations (positive, negative, or neutral) will obviously occur more frequently in large mating populations than in smaller ones, and new genetic variations affecting the brain's structure and function have been discovered as it continues to evolve in the 
ever changing challenges posed by new ecological and cultural conditions (Evans et al., 2005; Mekel-Bobrov et al., 2005).

Mithen and Parsons (2008) argue that culture has influenced both the anatomy and function of the human brain beyond the influences posed by the challenges of the physical environment. A number of studies of hominid crania dating back to 1.9 million years have shown that cranial capacity increases most rapidly in areas of the globe with greater population density and where food procurement was most problematic; that is, in the colder and most northerly areas (Ash and Gallup, 2007; Kanazawa, 2008). It has also been found that latitude $(r=0.61)$ and population density $(r=0.79)$ are strongly related to cranial size, leading to the conclusion that the burden of natural selection has moved from "climactic and ecological to social" Bailey and Geary (2009:77).

Of course, food procurement is more problematic in colder climates; and the more people there are in one's immediate culture, the more the number of social relationships one has to navigate. These challenges naturally lead to the selection for greater intelligence, which means more cerebral mass and bigger crania in which to house it. About two million years separate Australopithecus afarensis and Homo sapiens, and in this period, hominid cranial capacity has increased from an average of 450 to $1350 \mathrm{cc}$ which, on an evolutionary time scale, is warp speed (Adolphs, 2009).

One may point out that food procurement was also problematic in some southerly latitudes, such as in desert environments. However, cognitive demands increased among ancestral humans in northerly latitudes not simply because mean temperatures were lower, but rather because greater diversity of environments (moving from the abundance of summer to the scarcity of winter) required greater foresight. The differences between the seasons are more pronounced in northerly latitudes than in southerly latitudes. This necessitated the invention of shelters, storage facilities, tools, animal traps and weapons which were elaborated on across the generations. As Hoffecker (2002:135), points out: "Technological complexity in colder environments seems to reflect the need for greater foraging efficiency in settings where many resources are available only for limited periods of time." Desert dwellers simply adapted to a harsh but more stable environment which is highly unsuitable for the development of agriculture and cities. Consequently, they added little to their cultural artifacts and lived much the same way for countless generations.

Given that the brain has a voracious appetite for energy [it consumes $20 \%$ of the adult body's energy supply while being only $2 \%$ of total body mass (Mitchell, 2007)], it must have been vitally important to gene-culture co-evolution. Studies of a large range of animal species show that group size is related to brain size, leading neuroscientists to propose that the intellectual demands of living in large groups drove the selection for what they call the "social brain" (Lindenfors, 2005). The social brain enables us to negotiate relationships, to understand the thoughts, feelings, and intentions of others, and to cooperate in securing resources and in defending the group (Dunbar and Shultz, 2007). The alternative view of the link between brains and culture is that we acquired big brains and high intelligence without reference to selective pressures. The causal source for such a miraculous acquisition would have to be something akin to intelligent design (Baumeister et al., 2006).

Figure 1 from Walsh (2014) illustrates our argument in schematic form specifying the pathway from evoked culture to individual behavior. Ecological challenges evoked behaviors in ancestral populations that allowed them to overcome those challenges. These behaviors then became normative in a particular ecological niche, and members of that culture who possessed the traits best suited to that niche became more reproductively successful, resulting in the retention and proliferation of the genes underlying the adaptive traits. Behaviors and practices are then passed down in the form of transmitted culture via the socialization process, and may remain normative and perhaps adaptive even though the ecological conditions have changed.

The human genome is the chemical archive of millions of years of accumulated evolutionary wisdom. Culture serves as a conduit for the selection of genetic variants, and these variants then motivate their carriers to select cultural practices congenial to them over other cultural practices (Kitayamama and Uskul, 2011). In addition to cultural transmission of practices across the generations, there will also be genetic transmission of traits favored by specific cultures. Individual members of cultures who enjoy a genetic advantage for expressing the behaviors and values emphasized in those cultures will enjoy greater fitness benefits and those traits will then proliferate in the gene pool of their cultures. For instance, demonstrations of fierce and violent behavior translates directly into reproductive success among the lowland Yanomamo. Males who have killed the most in inter-village warfare have on average three times as many wives and children than those who have killed least or not at all (Chagnon, 1988). Because of greater reproductive success, the

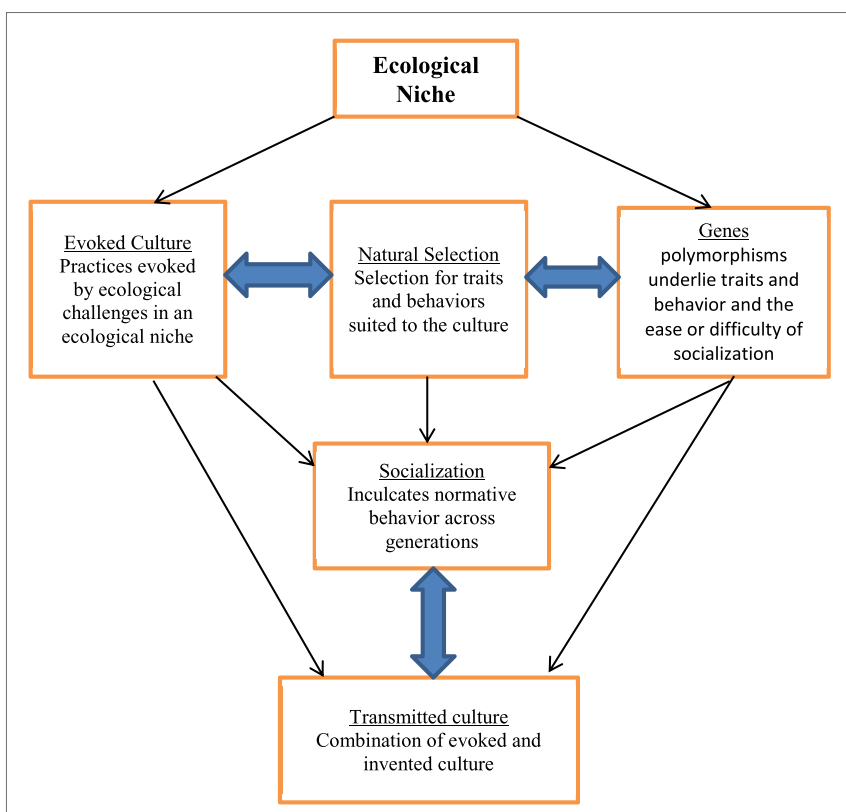

FIGURE 1 | Path from evoked culture to transmitted culture. Source: adapted from Walsh (2014). 
traits, behaviors, and values of the fiercest warriors will further differentiate between and among different cultures for genetic as well as for culturally transmitted reasons. We now provide examples of specific cultural practices associated with specific genetic variants.

\section{CULTURE AND THE SEROTONERGIC SYSTEM}

Serotonin [5-hydroxytriptamine (5-HT)] is the most studied neurotransmitter in behavioral science (Chiao and Blizinsky, 2010). Neurons containing 5-HT originate in the raphe nuclei in the midbrain and project to multiple areas of the brain. Figure 2 shows the diverse targets of 5-HT (black lines), which is consistent with the wide variety of behavior syndromes associated with neural 5-HT. Dopamine (DA) projections (white lines) are more or less limited to the prefrontal cortex (PFC) and various areas of the limbic system linked to pleasure (Stoltenberg and Nag, 2007). Excess neurotransmitters have to be quickly removed from the synaptic cleft after signaling to prevent confusion between that signal and subsequent signals. This is accomplished by the 5-HT transporter (5-HTT), which transports 5 -HT back into the presynaptic knob where it is repackaged. The 5 -HTT gene contains a region known as 5-HTTLPR ("serotonin transporter-linked polymorphous region") that comes in short (S) and long (L) versions. The short variant reduces the efficiency of the transporter system that results in decreased 5-HTT expression.
Caspi et al. (2003) examined the effects of the 5-HTTLPR polymorphism and maltreatment in a longitudinal birth cohort divided into maltreatment categories ("none," "probably," "severe"). Subjects homozygous for the short allele (S/S) had a greatly increased risk of a major depressive episode compared to other subjects. The probability of depression did not increase for subjects homozygous for the long allele (L/L) across the three maltreatment categories, and heterozygotes $(\mathrm{S} / \mathrm{L})$ were at intermediate risk. Looking at other patterns of adversity, the same pattern was evident. That is, the L/L genotype confers protection against adversity, the S/L confers some protection, and S/S individuals are most vulnerable. In other words, genotype mattered only in the face of environmental adversity, and environmental adversity only mattered to those with a particular genotype. A meta-analysis of 54 studies (Karg et al., 2011) found strong support for this particular $\mathrm{G} \times \mathrm{E}$. However, there have been a number of failures to replicate, and another meta-analysis reports that there is a small effect (as one would expect from examining a single polymorphism) and that publication bias may cloud the issue (Clarke et al., 2010). The diverse methodologies and measurement and the failure to take into consideration the full range of genetic and environmental variables also play a part in the controversy (Lewis et al., 2011).

It should also be made clear that the 5-HTTLPR polymorphism is not the only route to depression and anxiety. Problems may occur at any point of the serotonergic process, including low production of serotonin, insufficient receptor sites, the inability of serotonin to reach the receptor sites, enzymatic activity or low

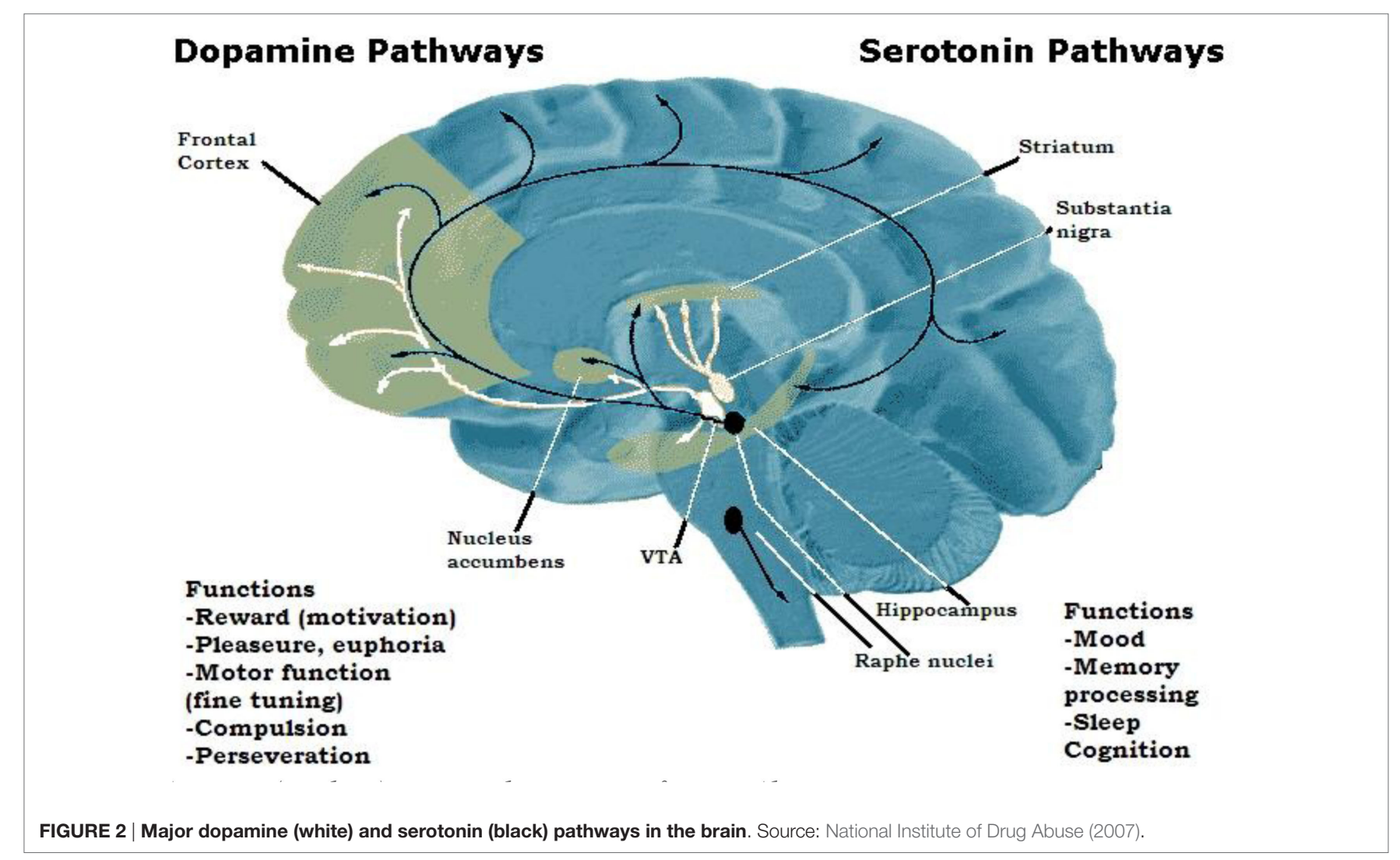


levels of dietary tryptophan, the chemical precursor of serotonin. What we do know with relative certainty is that brain serotonin regulates mood, social behavior, libido, sleep, memory, and learning, and that selective serotonin reuptake inhibitors (SSRI) improve problems in these areas for most, but not all, individuals (Schneck et al., 2016). Furthermore, the deficient functioning of many other neurochemicals, such as gamma-amino-butyric acid, glutamate, and norepinephrine contribute to anxiety disorders (Gilhotra and Dhingra, 2010), as well as brain-derived neurotropic factor (BDNF; a protein involved in neuron and synaptic development). However, we cannot get into all these nuanced processes here, focusing as we do on the broad issue of the influence of the prevalence of the 5-HTTLPR on cultural differences in specific behaviors.

\section{COLLECTIVISM, 5-HTTLPR POLYMORPHISMS, AND PSYCHOLOGICAL IMMUNITY}

Given the evidence cited above, we would, thus, expect S/S and $\mathrm{S} / \mathrm{L}$ individuals to avoid risks and to be hypervigilant to threat, and to be less inclined to engage in deviant behavior and to readily conform. We should also expect that cultural populations with a great prevalence of individuals carrying the short allele to have a greater prevalence of anxiety and depression. A meta-analysis of fMRI studies showed that individuals with the short variant of 5-HTTLPR tend to have heightened amygdala sensitivity; that is, the amygdala fires sooner, stronger, and more frequently (Munafo et al., 2008). The amygdala, a major target for serotonin, provides emotional emphasis (especially fear) to experiences that moves us to focus on how to avoid risks and dangers. But this is just a hypothesis that has produced both supportive and null findings [see Schneck et al. (2016), for a review].

Despite the fact that supportive findings in $\mathrm{G} \times \mathrm{E}$ interaction studies may sometimes be false for a variety of (correctible) reasons (Hewitt, 2012), they remain the best way we have to take both nature and nurture into consideration simultaneously. For this reason, it is relatively uncontroversial among a growing number of modern social scientists to acknowledge the usefulness of studies of behavioral differences among individuals produced by them. However, it is still controversial to explore interactions between genetics and cultural practices $(\mathrm{G} \times \mathrm{C})$ that are assumed to result in different patterns of behavior in different cultures. Nevertheless, such studies are proliferating in cultural psychology, social neuroscience, and genetics, particularly with respect of the 5-HTTLPR polymorphism (Kim and Sasaki, 2014).

East Asian Americans (Chinese, Japanese, and Koreans) are extolled as the "model minority" because all objective measures of prosocial behavior place them at the top of the list compared to other racial/ethnic groups (Chou, 2009), and all measures of criminal activity (arrest and imprisonment rates) place them at the bottom (Johnson and Betsinger, 2009). A nationwide study of Asian Americans noted that despite starting out at the bottom of the social ladder Asian Americans are widely viewed today as hardworking, successful, and law-abiding (Taylor, 2013).

Many scholars tend to attribute the admirable accomplishments and behavior of East Asians to Confucianism (Yun,
2008). Confucianism is a set of moral/ethical cultural norms and values stressing filial piety, humility, self-control, respect for elders, conformity to rules of behavior and respect for authority, among other things. This system of values is designed to create virtuous people who can live harmoniously within their social groups (Yun, 2008). All East Asian countries are not immersed in Confucianism as is China and South Korea, of course, but all have been influenced by it. Shintoism is the major religion in Japan, but because Shinto lacks a major ethical/moral code, bureaucrats have been anxious to incorporate this aspect of it in Shintoism (Toshio et al., 1981). As Hiroyuki (2006) points out: "An order is also found from the seventh year of the chronicle for Empress Jitō's reign (690-697) to 'promote Confucianism,' showing clearly that the influence of Confucianism started early." The Confucian creed has endured for 2,500 years and has to a great extent succeeded in its goal, but what might account for the extraordinary resilience of this code? After all, other cultures have attempted to transmit similar codes of conduct down the generations with less success.

The 5-HTTLPR polymorphism has been interrogated and has provided a partial answer to this intriguing question. Lieberman (2009:100) writes that: "The prevalence of short 5-HTTPR polymorphism in individuals of East Asian descent suggests that they may possess the kind of neurochemistry that would predispose them toward interdependence, establishing this as a cultural value, or enduring Big Idea [Confucianism], in this region of the world." In other words, the peoples of various cultures find some ideas and values congenial to them because of the fit between their brain chemistry and what these values prescribe and proscribe.

About 75\% of East Asians carry at least one short allele of the 5-HTTLPR compared with about $44 \%$ of Europeans (Chiao and Blizinsky, 2010), and about 20\% of Africans (Lotrich et al., 2003). Although the 5-HTTLPR prevalence data are consistent with the hypothesis that high anxiety and harm avoidance is a protective factor against antisocial behavior, fewer East Asians than Europeans or Africans are diagnosed with depression and anxiety disorders (Mrazek et al., 2013). To understand why populations with a high prevalence of an allele associated with these disorders in Western cultures have a low prevalence of these disorders we turn to gene-culture co-evolution.

Pathogen-borne diseases have historically posed substantial survival and reproductive challenges to humans, and they have been a major force guiding human evolution (Fincher et al., 2008). Natural selection's response was to construct an immune system, and some researchers have hypothesized that historically high levels of environmental pathogens also imposed selective pressures on social behaviors that resulted in a behavioral “immune system" (Fincher et al., 2008; Murray et al., 2011). They suggest that behavioral manifestations of collectivism, such as strong conformity, fear of outsiders, and ethnocentrism, evolved as anti-pathogen defenses ("Fear and avoid strangers; they may be diseased"). Fincher et al. (2008) examined the hypothesis that individualism-collectivism scores would be associated with historically high prevalence of pathogens among over 100,000 individuals from 68 countries and found individualism to be strongly $(r=-0.69)$ related to historically low pathogen prevalence. 
Chiao and Blizinsky (2010:3) build on this and argue that attitudes and behaviors serving an anti-pathogen function should also serve an anti-psychopathology function, and that both functions are served in part by a high prevalence of the short allele of the 5-HTTLPR in the population: "Collectivist cultural values serve an adaptive function by reducing the probability of environmental stress, a known catalyst for negative affect, thus leading to genetic selection of the $S$ allele within collectivist cultures." They also note that an active amygdala confers advantages in conformist groups because it serves as an early warning system (anxiety) alerting individuals to signs of disapproval of other members of the group. Members of collectivist cultures also tend to define their self-worth in relation to the collectivity and their contribution to it (Yun, 2008), which may lead to less anxiety and depression, despite the abundant presence of the short allele that is so salient in developing those problems in individualist countries. Thus, behaviors that would seem overly conformist and submissive in individualist cultures appear to be adaptive in collectivist cultures.

Highly individualist countries, such as the U.S., UK, and Australia have a lower prevalence of the short allele than most other countries, and China, Singapore, Korea, and Taiwan had the highest collectivist scores and the highest prevalence of the short allele of all countries. The correlation between the prevalence of the short allele and collectivism over all 29 countries for which genetic data were available was $0.70, p<0.0001$. Chiao and Blizinsky (2010:6), conclude: "Emphasizing social norms that increase social harmony and encourage giving social support to others, collectivism serves an 'anti-psychopathology' function by creating an ecological niche that lowers the prevalence of chronic life stress, protecting genetically susceptible individuals from environmental pathogens known to trigger negative emotions and psychopathology."

Mrazek et al. (2013) examined the 5-HTTLPR polymorphism in 51,135 individuals from 29 cultures they defined as either "tight" or "loose." Tight (restrictive) cultures have strong social norms with low tolerance for deviation. Loose (permissive) cultures are more open to attitudinal and behavioral deviation. While tightness/looseness (TL) is hypothesized to be a function of many of the same threat levels experienced by ancestral generations that lead to collectivism/individualism (CI), the former pertains to norm enforcement, while the latter pertains to the strength of social ties to in-groups. TL and CI are strongly related, but far from perfect. For example, North Korea is far "tighter" than South Korea but both are collectivist cultures. Mrazek et al. (2013) found that TL was strongly related to the frequency of S alleles in a culture $(r=0.65)$, and the allelic frequency was related also to historical ecological threat $(r=0.559)$. The hypothesis is, thus, that cultural collectivism involving more caring social relations and support networks might buffer individuals in genetically susceptible populations against the symptoms of affective disorder relative to individuals in more individualist populations. Carriers of S alleles (particularly S/Ss) may be expected to have a greater sensitivity to cues of rejection from the social connections in which they are immersed and experience heightened concern over the consequences. This could lead to the subjugation of selfinterest in favor of groups interest; the defining characteristic of collectivism. It is via processes such as this that genes interact with culture and reinforce its norms (Kitayama et al., 2016).

\section{THE DOPAMINERGIC SYSTEM AND BEHAVIORAL REGULATING SYSTEMS}

As seen in Figure 2, DA underlies motivation and pleasure. Neurons whose principle neurotransmitter is DA are found in the ventral tegmental area (VTA) and substantia nigra (SN), both of which are involved in reward. It is adaptive for all social animals to respond to signals of reward and punishment with socially appropriate approach and avoidance behavior. Natural selection has built neurological systems to regulate such behavior in ways that are functional for individuals and, thus, for their social groups. Reward sensitivity theory (RST) is a neurobiological theory of behavioral regulation that posits three interacting systems with their separate but integrated brain circuits and neurotransmitter systems: the behavioral activating system (BAS), the behavioral inhibition system (BIS), and the fight-flight-freeze system (FFFS) (Corr, 2004; Cooper et al., 2007). The BAS and BIS are part of the central nervous system and have feedback loops between the "emotional" limbic system and the "rational" PFC. The FFFS is part of the peripheral nervous system's autonomic nervous system. For the sake of brevity, and because the BAS and BIS are the primary systems, we limit our discussion to them.

The BAS is sensitive to signals of reward and is primarily associated with DA and with limbic structures such as the VTA, which is rich in neurons that synthesize dopamine, and with the nucleus accumbens, a pleasure center after activated by DA (Day and Carelli, 2007). The BAS is nature's built-in reward system motivating animals to seek things vital to survival and reproductive success (food, water, sex), but in evolutionarily novel environments, a "reward dominant" brain leads to physical, social, and legal difficulties, such as addiction to gambling, food, sex, alcohol, and drugs (Walsh et al., 2012). The BIS engages when BAS activity is exceeding normal limits to prevent this in most of us. It does this by inducing feelings of fear and anxiety in anticipation of negative consequences. The BIS is the neurological equivalent of Freud's superego applying the moral "brakes" to his id, the incessant search for pleasure (Schilling et al., 2011). The BIS is chemically activated by serotonin, which operates on limbic structures, such as the hippocampus and the amygdala that feed their memory circuits into the PFC where judgments are made (Blair, 2007). Just as the BAS can exceed its optimum, so can the BIS. An overly active BIS is related to anxiety-related disorders, such as obsessive-compulsive disorder, but an underactive one is correlated with ADHD and psychopathy (Amodio, et al., 2007). An understanding of the serotonergic and dopaminergic systems is, thus, very useful for understanding many aspects of human behavior.

\section{DOPAMINE RECEPTORS AND CULTURAL VARIATION}

Because dopamine is the "approach" half of the approach/avoidance system, it has also been a target for social neuroscientists and geneticists seeking a deeper understanding of culture, 
although the $\mathrm{G} \times \mathrm{C}$ literature is nowhere near as extensive as it is on serotonin. Neurotransmitters must have receptor molecules with which to dock. There are five subtypes of DA receptors, but we limit our discussion to the DRD4. The DRD4 is a highly polymorphic gene that comes in long and short forms of 48 bases that repeat between 2 and 11 times (KeltikangasJärvinen and Salo, 2009). The 2- and 7-repeats of the DRD4 are associated with less efficient DA feedback inhibition and contribute to reward dominant brains that require high levels of stimulation to activate their pleasure systems (DeLisi et al., 2009; Kitayama et al., 2014). Studies have determined that about $65.1 \%$ of individuals have the $4 \mathrm{R}$ allele (the parent allele) of the DRD4 gene, $19.2 \%$ have the $7 \mathrm{R}, 8.8 \%$ the $2 \mathrm{R}$, and the remaining $6.9 \%$ having one of the other rare repeats (Ding et al., 2002). The 7-repeat (7R) allele of the DRD4 is most often studied because of its association with a variety of syndromes, such as ADHD and novelty seeking.

Haplotype linkage disequilibrium patters (a haplotype is a set of polymorphisms that tend to be inherited together) suggest that the DRD4-7R allele is a young mutation that arose about 40,000 years ago and has been positively selected for (ArcosBurgos and Acosta, 2007; Kitayama et al., 2016). Positive selection indicates that some traits, such as impulsivity, aggression, and novelty seeking associated with this allele were adaptive at certain times and in certain environments in the past. The emergence of the $7 \mathrm{R}$ mutation 40,000 years ago coincides roughly with the first signs of the emergence of complex horticultural/agricultural societies, and with the time humans were exploring and expanding widely around the planet (Eisenberg et al., 2008).

Charles Darwin (1871:172) suggested the major adaptive function served by the restlessness characterized by $7 \mathrm{R}$ carriers: "Restless men who will not follow any steady occupation - and this relic of barbarism is a great check to civilisation - emigrate to newly-settled countries, where they prove useful pioneers." Of course, neither Darwin nor anyone else at the time knew about genes. He was simply making an astute observation that was later vindicated by science in the same way that Dalton's intuition about atoms and Plato's observations of human approach/ avoidance were later vindicated.

Consistent with Darwin's observation is a study of 2,320 individuals from 39 different ethnic groups from around the world reporting a correlation between the prevalence of the $7 \mathrm{R}$ allele in a population and geographic distance from the parent population of 0.85 (Ding et al., 2002). The Han Chinese and Yemeni Jews who have remained in the same geographic region for the last 30,000 years have practically zero 7R alleles, while six populations of South American Indians have an average of $63 \%$, which is about 3.3 times greater than the global average (Ding et al., 2002). Matthews and Butler (2011:388), conducted a similar analysis controlling for neutral (non-selective) processes, such as drift and admixture, and added the $2 \mathrm{R}$ to their models. They concluded that: "The coalescence time, genetic signature of selection, and observed association with migratory distance are all highly consistent with the hypothesis that increased frequency of $2 \mathrm{R}$ and $7 \mathrm{R}$ exon [the protein coding segment of the gene] VNTRs [variable number of tandem repeats] have been selected by repeated generations of migration."
As the above statement by Matthews and Butler (2011) suggests, the $7 \mathrm{R}$ allele should not be seen as "causing" its carriers to migrate from the parent population and explore the outside world. The prevalence of this allele is not significantly greater than expected by chance among recent European immigrant to the United States and East Asians, suggesting that $7 \mathrm{R}$ carriers are not any more prone to migrate than the carriers of any other DRD4 variant. Because the $7 \mathrm{R}$ is a relative young mutation (Arcos-Burgos and Acosta, 2007), it is more likely that migration itself exerted pressures for the selection of the allele since restless and bold individuals would have functioned better in novel environments (Matthews and Butler, 2011). The 7R allele is well represented among groups with a reputation for boldness, restlessness, and fierceness: "It is probably no accident that two of the best known ethnographies of the twentieth century are titled 'The Harmless People,' about the!Kung who have few or no 7R alleles, and the 'Fierce People, about the Yanomamo with a high frequency of 7R" (Harpending and Cochran, 2002:12).

Just as the SS polymorphism is both advantageous and disadvantageous depending on the environment in which it is expressed, so is the DRD4-7R allele. Eisenberg et al. (2008) took advantage of the split of the Ariaal tribe of Kenya into two groups in 1972 to perform a quasi-experiment. Half of the tribe retained their traditional nomadic life, while the other settled down in villages. Members of the tribe that maintained the nomadic ways and who also carry the $7 R$ tended to be stronger and better nourished than their non-7 $R$ peers, implying greater reproductive success and the proliferation of the allele. Eisenberg et al. (2008:6), note that the traits underlain by the $7 \mathrm{R}$ would allow "nomadic children to more readily learn effectively in a dynamic [non-school] environment, while the same attention span interferes with classroom learning." It was also noted that among the Ariaal living in settled villages $7 R$ carriers tend to be less strong and well-nourished than carriers of other alleles. The fitness value of the $7 R$, thus, depends upon the cultural context in which it finds itself. A restless person may thrive in a changeable environment but in a stable environment will do less well, as will the allele in future generations.

\section{CONCLUSION}

The notion of evoked culture reveals the complex dance of geneculture co-evolution. Transmitted culture is hugely important in explaining variation in human behavior across time and place, and it certainly suffices to explain transient modes of fashion, music art, technology, science, culinary preferences, morality, and many other things. However, when it comes to fundamental concerns about survival and reproductive success, we must not view culture ontologically distinct from biology. It is true that the nuances of cultural life are lost as we move from proximate to ultimate level explanations, but ultimate level explanations complement proximate explanations; they do not compete with them, and they add many fine nuances of their own. A host of sociological issues, such as marriage and the family, religion, crime, and cooperation and conflict, can slot into the framework of connective tissue provided by gene-culture co-evolution.

We have seen examples that the plastic human genome is designed to render individuals responsive to environmental 
influences. While cooperation, affiliation, conformity, and social sensitivity are important in all cultures, the historical demands of Far Eastern cultures evoked collectivist practices more strongly than the historical ecological demands of Western cultures. The requirement for enhanced collectivism presumably resulted in positive selection of the short allele of the 5-HTTLPR in those populations, where it has positive consequences, while in more individualist Western cultures where it is far less prevalent, it is a putative "risk allele" for depression. In Far Eastern cultures, carriers of the $S$ allele have neural circuits that learn fear and avoidance conditioning faster and are more sensitive to cues that they are not conforming to cultural norms.

Likewise, the $7 \mathrm{R}$ of the DRD4 gene has been shown to be both biologically and culturally adaptive in some contexts and in some historical periods, but may be maladaptive in the context of modern societies. There is a constant two-way dance between the genome and its environment such that the effects of the environment depend on genetics and the effects of genetics depend on the environment. As Baker et al. (2006:44), have put it: "The more we know about the genetics of behavior, the more important the environment appears to be." Traditional sociologists have worried themselves silly about "genetic determinism," but we know that there is no such thing. There are no genes "for" complex behaviors, such as collectivism or individualism, just as there are no genes "for" crime, alcoholism, or violence. Genes are simply chemical structures that code for amino acid sequences of proteins. These proteins interact with phenotypes, the situations we find ourselves in, and with other proteins coded for by other genes.

Although we have concentrated on two isolated polymorphisms, it should be emphasized that the number of possible permutations of genes and environments needed to account for any complex behavior is considerable. For instance, a meta-analysis of

\section{REFERENCES}

Adolphs, R. (2009). The social brain: neural basis of social knowledge. Annu. Rev. Psychol. 60, 693-716. doi:10.1146/annurev.psych.60.110707.163514

Amodio, D., Devine, P., and Harmon-Jones, E. (2007). A dynamic model of guilt: implications for motivation and self-regulation in the context of prejudice. Psychol. Sci. 18, 524-530. doi:10.1111/j.1467-9280.2007.01933.x

Anderson, E. (1999). Code of the Street: Decency, Violence, and the Moral Life of the Inner City. New York: W.W. Norton.

Arcos-Burgos, M., and Acosta, M. (2007). Tuning major gene variants condition human behavior: the anachronism of ADHD. Curr. Opin. Genet. Dev. 17, 234-238. doi:10.1016/j.gde.2007.04.011

Ash, J., and Gallup, G. (2007). Paleoclimatic variation and brain expansion during human evolution. Hum. Nat. 18, 109-124. doi:10.1007/s12110-007-9015-z

Badcock, C. (2000). Evolutionary Psychology: A Critical Introduction. Cambridge, England: Polity Press.

Bailey, D., and Geary, D. (2009). Hominid brain evolution: testing climactic, ecological, and social competition models. Hum. Nat. 20, 67-79. doi:10.1007/ s12110-008-9054-0

Baker, L., Bezdjian, S., and Raine, A. (2006). Behavior genetics: the science of antisocial behavior. Law Contemp. Probl. 69, 7-46.

Barber, N. (2003). The sex ratio and female marital opportunity as historical predictors of violent crime in England, Scotland, and the United States. Cross Cult. Res. 37, 373-392. doi:10.1177/1069397103254011

Baumeister, R., Maner, J., and DeWall, N. (2006). Evoked culture and evoked nature: coevolution and the emergence of cultural animals. Psychol. Inq. 17, $128-130$.
2,343 lines of evidence identified no less than 316 genes related to drug addiction and 13 addiction-related pathways (Li et al., 2008). These pathways involve a number of neurotransmitters, receptor, transporter, and enzymatic genes. Genes can only indirectly affect complex behavior by influencing our sensitivities to particular environments, situations, and substances, and thus may evoke certain behaviors, but they do not do so by themselves. As a discipline, sociology should embrace the gifts offered by the natural sciences rather than turn its back on them. Genes are at the beck and call of their carriers, constantly responding to their needs by making the hormones, neurotransmitter, and cell-structure proteins needed to meet environmental challenges; their carriers are not at the beck and call of genes.

Indeed a number of philosophers and scientists see genetics as the foundation of free will in that they allow us to follow the inclinations of our own natures when conditions permit. Steven Rose (2001:6) writes: "Individually and collectively we have the ability to construct our own futures, albeit in circumstances not of our own choosing. Thus it is that our biology makes us free." Likewise, Christopher Badcock (2000:71), asserts that our genes "positively guarantee" human freedom and agency. If genes incline us in one direction rather than another, we are being nudged internally, not by something wholly outside of ourselves. After all, our genes are our genes. Likewise, the more we come to appreciate how natural scientists view issues of human agency in relation to biology, the more we will appreciate how erroneous the charges of biological determinism and the more we will appreciate the necessity to study social issues from multiple levels of analysis ranging from neurons to neighborhoods.

\section{AUTHOR CONTRIBUTIONS}

AW and IY contributed equally to writing this paper.

Blair, R. (2007). The amygdala and ventromedial prefrontal cortex in morality and psychopathy. Trends Cogn. Sci. 11, 387-392. doi:10.1016/j. tics.2007.07.003

Brown, G., Dickins, T., Sear, R., and Laland, K. (2011). Evolutionary accounts of human behavioural diversity. Philos. Trans. R. Soc. Lond. B Biol. Sci. 366, 313-324. doi:10.1098/rstb.2010.0267

Burman, J. (2012). The misunderstanding of memes: biography of an unscientific object, 1976-1999. Perspect. Sci. 20, 75-104. doi:10.1162/POSC_a_00057

Buss, D. (2001). Human nature and culture. J. Pers. 68, 978.

Caspi, A., Sugden, K., Moffitt, T., Taylor, A., Craig, I., Harrington, H., et al. (2003). Influence of life stress on depression: moderation by a polymorphism in the 5-HTT gene. Science 301, 386-389. doi:10.1126/science.1083968

Census Bureau US. (2014). America's Families and Living Arrangements: 2013. Available at: http://www.census.gov/hhes/families/data/cps2013A.html

Chagnon, N. (1988). Life histories, blood revenge, and warfare in a tribal population. Science 239, 985-992. doi:10.1126/science.239.4843.985

Chiao, J., and Blizinsky, K. (2010). Culture-gene coevolution of individualism-collectivism and the serotonin transporter gene. Proc. Biol. Sci. 277, 529-537. doi:10.1098/rspb.2009.1650

Chou, S. (2009). Critique in the Notion of Model Minority: An Alternative Racism to Asian American? Research Express. Available at: http://research.ncku.edu.tw/ re/articles/e/20090619/3.html

Clarke, H., Flint, J., Attwood, A. S., and Munafo, M. R. (2010). Association of the 5-HTTLPR genotype and unipolar depression: a meta-analysis. Psychol. Med. 40, 1767-1778. doi:10.1017/S0033291710000516

Cohen, A. (2010). Just how many different forms of culture are there? Am. Psychol. 65, 59-61. doi:10.1037/a0017793 
Cooper, A., Perkins, A., and Corr, P. (2007). A confirmatory factor analytic study of anxiety, fear, and behavioral inhibition system measures. J. Individ. Diff. 4, 179-187. doi:10.1027/1614-0001.28.4.179

Corr, P. (2004). Reinforcement sensitivity theory and personality. Neurosci. Biobehav. Rev. 28, 317-332. doi:10.1016/j.neubiorev.2004.01.005

Darwin, C. (1871). The Descent of Man, and Selection in Relation to Sex. London: J. Murray.

Dawkins, R. (2006). The Selfish Gene: With a New Introduction by the Author. Oxford: Oxford University Press.

Day, J., and Carelli, R. (2007). The nucleus accumbens and Pavlovian reward learning. Neuroscientist 13, 148-159. doi:10.1177/1073858406295854

DeLisi, M., Beaver, K., Vaughn, M., and Wright, J. (2009). All in the family: gene $\mathrm{x}$ environment interaction between DRD2 and criminal father is associated with five antisocial phenotypes. Crim. Justice Behav. 36, 1187-1197. doi:10.1177/0093854809342884

Ding, Y., Chi, H., Grady, D., Morishima, A., Kidd, J., Kidd, K., et al. (2002). Evidence of positive selection acting at the Human dopamine receptor D4 gene locus. Proc. Natl. Acad. Sci. U.S.A. 99, 309-314. doi:10.1073/pnas.012464099

Dunbar, R., and Shultz, S. (2007). Evolution of the social brain. Science 317, 1344-1347. doi:10.1126/science. 1145463

Eisenberg, D., Campbell, B., Gray, P., and Sorenson, M. (2008). Dopamine receptor genetic polymorphisms and body composition in undernourished pastoralists: an exploration of nutrition indices among nomadic and recently settled Ariaal men of northern Kenya. BMC Evol. Biol. 8:173. doi:10.1186/1471-2148-8-173

Evans, P., Gilbert, S., Mekel-Bobrov, N., Vallender, E., Anderson, J., Vaez-Azizi, L., et al. (2005). Microcephalin, a gene regulating brain size, continues to evolve adaptively in humans. Science 309, 1717-1720. doi:10.1126/science.1113722

Fincher, C., Thornhill, R., Murray, D., and Schaller, M. (2008). Pathology prevalence predicts human cross-cultural variability in individualism/collectivism. Proc. Biol. Sci. 275, 1279-1285. doi:10.1098/rspb.2008.0094

Flinn, M. (2010). Evolution is not egalitarian. Curr. Anthropol. 51, 103-104. doi:10.1086/649565

Gewertz, D., and Errington, F. (1991). Twisted Histories, Altered Contexts: Representing The Chambuli in a World System. Cambridge: Cambridge University Press.

Gilhotra, N., and Dhingra, D. (2010). Neurochemical modulation of anxiety disorders. Int. J. Pharm. Pharm. Sci. 2(Suppl. 1), 1-6.

Guttentag, M., and Secord, P. (1983). Too Many Women: The Sex Ratio Question. Beverly Hills, CA: SAGE.

Harpending, H., and Cochran, G. (2002). In our genes. Proc. Natl. Acad. Sci. U.S.A. 99, 10-12. doi:10.1073/pnas.012612799

Harpending, H., and Draper, P. (1988). "Antisocial behavior and the other side of cultural evolution," in Biological Contributions to Crime Causation, eds T. Moffitt and S. Mednick (Dordrecht: Martinus Nyhoff), 293-307.

Hawks, J., Wang, E., Cochran, G., Harpending, H., and Moyzis, R. (2007). Recent acceleration of human adaptive evolution. Proc. Natl. Acad. Sci. U.S.A. 104, 20753-20758. doi:10.1073/pnas.0707650104

Hewitt, J. K. (2012). Editorial policy on candidate gene association and candidate gene-by-environment interaction studies of complex traits. Behav. Genet. 42, 1-2. doi:10.1007/s10519-011-9504-Z

Hiroyuki, Y. (2006). "Shinto and Confucianism," in Encyclopedia of Shinto. Available at: http://eos.kokugakuin.ac.jp/modules/xwords/entry.php?entryID=827

Hoffecker, J. (2002). Desolate Landscapes. Ice-Age Settlement in Eastern Europe. New Brunswick, NJ: Rutgers University Press.

Johnson, B., and Betsinger, S. (2009). Punishing the "model minority": AsianAmerican criminal sentencing outcomes in federal district courts. Criminology 47, 1045-1090. doi:10.1111/j.1745-9125.2009.00169.x

Kanazawa, S. (2008). Temperature and evolutionary novelty as forces behind the evolution of general intelligence. Intelligence 36, 99-108. doi:10.1016/j. intell.2007.04.001

Karg, K., Burmeister, M., Shedden, K., and Sen, S. (2011). The serotonin transporter promoter variant (5-HTTLPR), stress, and depression meta-analysis revisited. Arch. Gen. Psychiatry 68, 673-680. doi:10.1001/archgenpsychiatry.2010.189

Kashima, Y. (2016). Culture and psychology in the 21st century conceptions of culture and person for psychology revisited. J. Cross Cult. Psychol. 47, 4-20. doi:10.1177/0022022115599445

Keltikangas-Järvinen, L., and Salo, J. (2009). Dopamine and serotonin systems modify environmental effects on human behavior: a review. Scand. J. Psychol. 50, 574-582. doi:10.1111/j.1467-9450.2009.00785.x
Kim, H., and Sasaki, J. (2014). Cultural neuroscience: biology of the mind in cultural context. Annu. Rev. Psychol. 65, 487-514. doi:10.1146/annurev-psych010213-115040

Kitayama, S., King, A., Hsu, M., Liberzon, I., and Yoon, C. (2016). Dopaminesystem genes and cultural acquisition: the norm sensitivity hypothesis. Curr. Opin. Psychol. 8, 167-174. doi:10.1016/j.copsyc.2015.11.006

Kitayama, S., King, A., Yoon, C., Tompson, S., Huff, S., and Liberzon, I. (2014). The dopamine D4 receptor gene (DRD4) moderates cultural difference in independent versus interdependent social orientation. Psychol. Sci. 25, 1169-1177. doi:10.1177/0956797614528338

Kitayamama, S., and Uskul, A. (2011). Culture, mind, and the brain: current evidence and future directions. Annu. Rev. Psychol. 62, 419-449. doi:10.1146/ annurev-psych-120709-145357

Laland, K., dling-Smee, J. O., and Myles, S. (2010). How culture shaped the human genome: bringing genetics and the human sciences together. Nat. Rev. Genet. 11, 137-148. doi:10.1038/nrg2734

Layton, R. (2010). Why social scientists don't like Darwin and what can be done about it. J. Evol. Psychol. 8, 139-152. doi:10.1556/JEP.8.2010.2.4

Lewis, G., Mulligan, J., Wiles, N., Cowen, P., Craddock, N., Ikeda, M., et al. (2011). Polymorphism of the 5-HT transporter and response to antidepressants: randomised controlled trial. Br. J. Psychiatry 198, 464-471. doi:10.1192/bjp. bp. 110.082727

Li, C., Mao, X., and Wei, L. (2008). Genes and (common) pathways underlying drug addiction. PLoS Comput. Biol. 4:e2. doi:10.1371/journal.pcbi.0040002

Lieberman, M. (2009). "What makes big ideas stick?," in What's Next: Dispatches on the Future of Science, ed. M. Brockman (New York: Vintage), 90-103.

Lindenfors, P. (2005). Neocortex evolution in primates: the "social brain" is for females. Biol. Lett. 1, 407-410. doi:10.1098/rsbl.2005.0362

Lipset, D. (2003). Rereading sex and temperament: Margaret Mead's Sepik triptych and its ethnographic critics. Anthropol. Q. 76, 693-713. doi:10.1353/ anq. 2003.0058

Loch, C., Galunic, D., and Schneider, S. (2006). Balancing cooperation and competition in human groups: the role of emotional algorithms and evolution. Manag. Decis. Econ. 27, 217-233. doi:10.1002/mde.1294

Lotrich, F., Pollock, B., and Ferrell, R. (2003). Serotonin transporter promoter polymorphism in African Americans: allele frequencies and implications for treatment. Am. J. Pharmacogenomics 3, 145-147. doi:10.2165/00129785200303020-00007

MacDonald, K. (1997). Life history theory and human reproductive behavior. Hum. Nat. 84, 327-359. doi:10.1007/BF02913038

Massey, D. (2002). A brief history of human society: the origin and role of emotion in social life. Am. Sociol. Rev. 67, 1-29. doi:10.2307/3088931

Matthews, L., and Butler, P. (2011). Novelty-seeking DRD4 polymorphisms are associated with human migration distance out-of-Africa after controlling for neutral population gene structure. Am. J. Phys. Anthropol. 145, 382-389. doi:10.1002/ajpa.21507

McDermott, R., and Hatemi, P. (2014). Policical ecology: on the mutual formation of biology and culture. Polit. Psychol. 35, 111-127. doi:10.1111/pops.12165

Mead, M. (1935). Sex and Temperament in Three Primitive Societies. New York: Morrow.

Mekel-Bobrov, N., Gilbert, S., Evans, P., Vallender, E., Anderson, J., Hudson, R., et al. (2005). Ongoing adaptive evolution of ASPM, a brain size determinant in Homo Sapiens. Science 309, 1720-1722. doi:10.1126/science.1116815

Mesoudi, A. (2006). How cultural evolutionary theory can inform social psychology and vice versa. Psychol. Rev. 116, 929-952. doi:10.1037/a0017062

Mitchell, K. (2007). The genetics of brain wiring: from molecule to mind. PLoS Biol. 5:e113. doi:10.1371/journal.pbio.0050113

Mithen, S., and Parsons, L. (2008). The brain as a cultural artifact. Camb. Archeol. J. 18, 415-422. doi:10.1017/S0959774308000450

Moya, C., and Henrich, J. (2016). Culture-gene coevolutionary psychology: cultural learning, language, and ethnic psychology. Curr. Opin. Psychol. 8, 112-118. doi:10.1016/j.copsyc.2015.10.001

Mrazek, A., Chiao, J., Blizinsky, K., Lun, J., and Gelfand, M. (2013). The role of culture-gene coevolution in morality judgment: examining the interplay between tightness-looseness and allelic variation of the serotonin transporter gene. Cult. Brain 1, 100-117. doi:10.1007/s40167-013-0009-x

Munafo, M. R., Brown, S. M., and Hariri, A. R. (2008). Serotonin transporter (5HTTLPR) genotype and amygdala activation: a meta-analysis. Biol. Psychiatry 63, 852-857. doi:10.1016/j.biopsych.2007.08.016 
Murray, D., Trudeau, R., and Schaller, M. (2011). On the origins of cultural differences in conformity: four tests of the pathogen prevalence hypothesis. Pers. Soc. Psychol. Bull. 37, 318-329. doi:10.1177/0146167210394451

National Institute on Drug Abuse. (2007). The Neurobiology of Drug Addiction. Available at: https://www.drugabuse.gov/publications/teaching-packets/ neurobiology-drug-addiction

Nettle, D. (2009). Beyond nature versus culture: cultural variation as an evolved characteristic. J. R. Anthropol. Inst. 15, 223-240. doi:10.1111/j.1467-9655. 2009.01561.X

Roscoe, P. (2003). Margaret Mead, Reo Fortune, and Mountain Apapesh warfare. Am. Anthropol. 105, 581-591. doi:10.1525/aa.2003.105.3.581

Rose, S. (2001). Moving on from old dichotomies: beyond nature-nurture towards a lifeline perspective. Br J Psychiatry. 178, 3-7.

Schaller, M. (2006). Parasites, behavioral defenses, and the social psychological mechanisms through which cultures are evoked. Psychol. Inq. 17, 97-101.

Schilling, C., Walsh, A., and Yun, I. (2011). ADHD and criminality: a review of the genetic, neurobiological, evolutionary and treatment literature. J. Crim. Justice 39, 3-11. doi:10.1016/j.jcrimjus.2010.11.001

Schneck, N., Miller, J., Delorenzo, C., Kikuchi, T., Sublette, M., Oquendo, M., et al. (2016). Relationship of the serotonin transporter gene promoter polymorphism (5-HTTLPR) genotype and serotonin transporter binding to neural processing of negative emotional stimuli. J. Affect. Disord. 190, 494-498. doi:10.1016/j. jad.2015.10.047

Sober, E. (2007). "Sex ratio theory, ancient and modern - an 18th century debate about intelligent design and the development of models in evolutionary biology," in Genesis Redux: Essays in the History and Philosophy of Artificial Life, ed. J. Riskin (Chicago: University of Chicago Press), 131-162.

Stoltenberg, S., and Nag, P. (2007). "Applying control system modeling to understanding how genetic variation influences serotonin functioning and behavior," in Neural Synapse Research Trends, ed. J. Lassau (New York: Nova Science), $1-39$.

Taylor, P. (2013). The Rise of Asian Americans. Pew Research Center. Available at: http://www.pewsocialtrends.org/files/2013/04/Asian-Americans-new-fullreport-04-2013.pdf

Toshio, K., Dobbins, J., and Gay, S. (1981). Shinto in the history of Japanese religion. J. Jpn. Stud. 7, 1-21. doi:10.2307/132163

Turner, S. (2007). Social theory as cognitive neuroscience. Eur. J. Soc. Theory 10, 357-374. doi:10.1177/1368431007080700

Walsh, A. (2014). Biosociology: Bridging the Biology-Sociology Divide. New Brunswick, NJ: Transaction.

Walsh, A., and Bolen, J. (2012). The Neurobiology of Criminal Behavior: Gene-Brain Culture Co-Evolution. Farnham, England: Ashgate.

Walsh, A., Johnson, H., and Bolen, J. (2012). Drugs, crime, and the epigenetics of hedonic allostasis. J. Contemp. Crim. Justice 28, 314-328. doi:10.1177/ 1043986212450226

Yun, I. (2008). Wengu Zhisxin: review the old and know the new. Asia Pac. J. Police Crim. Justice 6, 3-23.

Conflict of Interest Statement: The authors declare that the research was conducted in the absence of any commercial or financial relationships that could be construed as a potential conflict of interest.

Copyright () 2016 Walsh and Yun. This is an open-access article distributed under the terms of the Creative Commons Attribution License (CC BY). The use, distribution or reproduction in other forums is permitted, provided the original author(s) or licensor are credited and that the original publication in this journal is cited, in accordance with accepted academic practice. No use, distribution or reproduction is permitted which does not comply with these terms. 